\title{
THE EFFECT OF TWO IMPLANT-ABUTMENT CONNECTIONS ON MAXIMUM BITE FORCE, PROSTHETIC MAINTENANCE AND PERI-IMPLANT SULCULAR FLUID IN MANDIBULAR IMPLANT SUPPORTED TELESCOPIC OVERDENTURE: A SPLIT-MOUTH STUDY
}

\author{
Iman A. El-Asfahani* and Amr M. Ismail **
}

\begin{abstract}
Purpose: The aim of this study was to evaluate and compare two different implant-abutment connections (conical and trilobe connection) in mandibular implant supported telescopic overdenture. The parameters of evaluation were the maximum bite force, prosthetic maintenance and peri-implant sulcular fluid.
\end{abstract}

Materials and method: Twelve completely edentulous patients received new complete dentures. After 3 months of adaption to the new denture, 24 implants (12 implants with conical implant-abutment connection (group A) and 12 implants with trilobe implant-abutment connection (group B). The Insertion of each type of implant was randomly assigned between the two contralateral sides intraorally for each patient using a statistical software. Each patient was treated according to split mouth design. The implants were inserted in the canine region of the mandible using two-stage surgical technique and conventional loading protocol. After 3 months, implants were exposed and a telescopic overdenture was constructed. The maximum bite force, prosthetic maintenance and peri-implant sulcular fluid for each group of implants were evaluated at loading time, after 6 and 12 months.

Results: There was no statistically significant difference in maximum bite force between group A and B the at loading time, but there was a statistically significant difference at 6 and 12 months follow up visits. The prosthetic maintenance events in group A were 1 event compared to 5 events in group B. There was no statistically significant difference between group A and B in the peri-implant sulcular fluid at loading time, 6 and 12 months follow up visits.

Conclusion: Within the limitations of this study, it can be concluded that the conical implantabutment connection is associated with increased maximum bite force compared to the trilobe Implant-abutment connection. Conical implant-abutment connection can provide a stable implant system with fewer prosthetic complications and maintenance services compared to trilobe implant -abutment connection.

* Lecturer of Removable Prosthodontics, Faculty of Dentistry, Minia University

**Associate Professor of Removable Prosthodontics, Faculty of Dentistry, Minia University. 


\section{INTRODUCTION}

Mandibular implant supported overdenture is a superior treatment option compared to complete denture as it enhances retention and stability, speech and mastication. ${ }^{1}$ Compared to fixed prothesis, it also provides better esthetics in patients with huge vertical bone loss and accessibility for hygiene measures. ${ }^{2}$ In 2002, a consensus stated that "the two-implants overdenture is the main and first choice treatment for complete edentulous mandible", superior to conventional complete denture. In 2008, a subsequent consensus statement concluded that implant supported mandibular overdentures improved patients' satisfaction and quality of life. ${ }^{3}$ Magnet, ball and socket, bar and telescopic attachments are used to retain mandibular overdentures. The telescopic attachment system -compared with other attachments- provides outstanding retention due to frictional fit between primary and secondary copings. It offers better distribution of forces, mechanical durability and reduced denture movement. It can offer a treatment option with increased retention, reduced prosthodontic maintenance, satisfactory mastication and improved phonetics. ${ }^{4-6}$

Stable and consistent implant-abutment connection is an important requirement for successful implant-supported overdentures. The implant-abutment connection controls the rotational and lateral stability of the implant-abutment joint, determining the implant-supported prosthetic stability. ${ }^{7}$ The implant-abutment connection varies according to design into the butt-joint nonconical passive-fit (indexed external or internal) and the active-fit conical connection design. Variations of internal connections include octagonal, hexagonal and trilobe designs. Conical designs vary by the degree of taper and anti-rotational features. ${ }^{8,9}$ This variety aimed to reduce failures in adaptation at the implant-abutment connection and to preserve the health of peri-implant tissues..$^{10}$ Manufacturers of implant systems aim to improve adaptation and stability of the implant-abutment connection. Consequently, reducing the mobility of this connection by creating physically tight connections with a high level of accuracy which is considered to be an important prerequisite for implant success. ${ }^{11}$ The occlusal load transmission and subsequent stress distribution to the adjacent bone at the bone-implant interface depends on the design of implant and the implant abutment connection, the loading protocol, the type of occlusion, the implants position and number, the type and amount of the adjacent bone. ${ }^{12}$ Better resistance to displacement due to excessive occlusal forces is provided by different abutment connections as stress/strain on the implant will increase therefore encouraging marginal bone loss. ${ }^{13}$ In a systematic review, it was determined that no endosseous dental implant systems can provide a complete seal at the implantabutment interface. Nevertheless, evidence showed that conical connection systems provide superior bacterial seal and resistance to abutment movement, fatigue loading, maximum bending, torque loss compared to other connection systems. ${ }^{14}$ Lower permeability to bacteria due to smaller gap in the conical implant-abutment connection compared to trilobe connection was deduced in an invitro study. ${ }^{15}$ Another invitro study concluded that the quantity of microleakage at implant-abutment connection was lesser in conical than in internal hex connection following the off-set cyclic tensile and compressive loading. ${ }^{16}$ Even though these features of conical connection might hypothetically lead to improved clinical results, no evidence is available. Furthermore, even within in vitro studies no consensus is provided. Actually, available comparative clinical studies investigated only the success rate and marginal bone loss in implants with different connection. Conical and nonconical connection systems have almost equivalent success and survival rates. However, conical connection systems appear to produce lower marginal bone loss 
in most cases. ${ }^{17,18}$ Several studies concluded that the implant-abutment connection influences the stresses and strains induced in peri-implant crestal bone..$^{19-21}$

The marginal gap between the implant and abutment in two-piece implants act as a bacterial reservoir interfering with peri-implant tissue health in close proximity to bone playing a role in the development of peri-implant inflammation(periimplantitis) and increased marginal bone loss. It was detected in both in vivo and in vitro studies. ${ }^{22}$ Prevention of microbial leakage at the implant -abutment connection is a major challenge for the construction of 2-stage implants in order to minimize inflammatory reactions. Several design modifications have been accomplished attempting to decrease the implantabutment gap, thereby reducing both its biological and mechanical draw backs. ${ }^{23}$ The chief factors identified as conceivable causes for the formation of microgap are physiological function, occlusal load, micromotion at the implant-abutment connection and manufacturing tolerance. ${ }^{24}$

Inflammatory cell content increase in areas close to implant-abutment connection is due to the adhesion and proliferation of bacteria on the biofilm that is formed at the implant abutment gap during soft tissue handling for prosthetic part insertion. ${ }^{25}$ Peri-implantitis is considered to be a serious complication and one of the most significant factors linked with late failure. Peri-implantitis is a consequence of the interaction between bacteria and the implant-bearing tissues and the host immune response. Peri-implant sulcular fluid (PISF) is the osmotically intermediated exudate initiated from the gingival vascular plexus and is the analog of gingival crevicular fluid (GCF) of natural teeth. Its way and rate of creation was stated to be similar to GCF. Consequently it was concluded that the implant sulci characteristics is similar to gingival sulci with respect to crevicular fluid flow and microbiota. ${ }^{26}$ Similar to the GCF, the PISF is a strong marker of the severity of inflammation and measuring its volume variations can be related to the improvement of the diagnosis and treatment of peri-implant disease. ${ }^{27}$ It was found that the PISF volume increased with the increase of the extent and degree of inflammation. ${ }^{28}$ The effect of various implant systems and implant-abutment connection types on PISF volume and flow is still unidentified. Also, the studies regarding the quantification of fluid leakage and passage between different connection designs are scarce. Most of them were invitro studies comparing implant-abutment microgaps and bacterial leakage.

Prosthetic complications are any mechanical damage of the implant or suprastructures. ${ }^{29}$ To assess an implant mandibular supported overdenture, the prosthetic maintenance is one of the chief factors. ${ }^{30}$ The implant-abutment accurate fit and abutment screw preload are mechanical factors affecting the success of implant therapy. The preload loss throughout the occlusal load while the prosthesis is in function encourages misfit of the implantabutment connection resulting in stress increase in the implant and connection components, and subsequently in the adjacent bone. This could cause screw fracture, abutment and prosthesis damage, demanding the replacement of the prosthesis. ${ }^{31}$ The probability of screw loosening declines when gaps between implant and abutment are minimalized..$^{32}$ It has been confirmed in laboratory researches that screw-related complications or fracture or loosening) are linked with implant abutment connection misfit. ${ }^{33,34}$ Increase in the spaces between the implant and abutment could result in elevation in stress states in the implant piece, connection components and surrounding bone. ${ }^{35}$ Additionally, few clinical researches on conical connection systems stated a decrease in the frequency of prosthetic complications. ${ }^{36,37}$ Information about the required prosthetic maintenance to keep the implant supported overdenture functional over time in relation to implant- abutment connection 
is deficient. This maintenance adds to the cost and affects the patient's satisfaction with the treatment. This aspect is important for the clinician as it may influence the choice of the implant type.

A principal indicator of the functional state and efficacy of the masticatory system is the generated bite force. It is an important variable to investigate efficiency of prosthetic rehabilitation. ${ }^{38}$ The capability to bite is governed by craniomandibular structures, including the muscles of mastication and the dentition, whether it is it natural or artificial. Maximum bite force (MBF) influences diet choice, which plays an important role in patient's general health and quality of life. ${ }^{39}$ Researchers reported significant improvement of masticatory efficiency and maximum bite force with implant supported overdentures compared to conventional complete dentures..$^{40-44}$ The masticatory force of completely edentulous patients is reduced to $20 \%-40 \%$ of that of dentulous healthy persons. Consequently, denture wearers may need up to seven times more chewing strokes to masticate food units than do dentulous individuals. ${ }^{45}$ It is generally acknowledged that maximum bite force improves significantly after implant treatment through higher muscle activity and bite forces. ${ }^{46}$ Enhancement of the masticatory efficiency and bite force is one of the chief reasons why patients seek dental rehabilitation. ${ }^{47}$ Most of research work was directed to evaluate of the mechanical performance of different implantabutment connections and most of them were invitro studies. There is a lack of evidence of the effect of different implant abutment connection designs on the masticatory efficiency and bite force of patients.

The aim of the study was to evaluate and compare two different implant-abutment connections (trilobe and conical connection) in mandibular implant supported telescopic overdenture. The parameters of evaluation were the maximum bite force, prosthetic maintenance and peri-implant sulcular fluid.

\section{MATERIAL AND METHODS}

\section{Participant selection and treatment}

Twelve completely edentulous patients (six males/ six females) were selected from the outpatient Clinic of the Prosthodontics Department; Faculty of Dentistry, Minia University, Egypt. Included participants were required to have well developed ridge with sufficient height and width allow implant insertion with $16 \mathrm{~mm}$ length, and $3.7 \mathrm{~mm}$ width, Class 1 Angle's classification with sufficient inter-arch distance. Participants with a history of radiotherapy in the head and neck region, smokers, bruxers or having any disease that could affect osteointegration were excluded. All patients participated in the study were informed about the nature of the study before signing an informed patient consent. The study was accepted by the ethical committee of the Faculty of Dentistry, Minia University.

A complete denture was constructed for each patient to aid in the dual scan technique for construction of surgical guide as the first scan was taken with patient wearing the denture with radiopaque martial used as scan markers (radiographic stent), the second scan was taken for the denture alone. The resulting CBCT images were converted to a digital imaging, and sent to the manufacturer construction of the 3D-printed surgical guide. The complete denture was constructed following conventional denture fabrication procedures. A preliminary impression was taken in irreversible hydrocolloid material (Cavex CA37, Normal Set, Holland) to obtain study casts. Final impression using a border molded autopolymerizing acrylic special tray (Palapress Vario Heraeus Kulzer, Hanau, Germany) and non-eugenol Zinc-oxide and eugenol (Cavex impression paste, Holland) to obtain the master cast. Maxillary and mandibular trial denture bases were constructed and used to record the jaw relations. Mounting the master casts on a semi-adjustable articulator (HANAU, Wide; Whip Mix Corporation, Farmington Ave, Louisville, KY, 
USA). The face bow record was used to mount the upper cast, and centric relation record with checkbite technique at the proper vertical dimension to mount the mandibular cast. Setting up of teeth with over contouring the wax at the mandibular anterior area. The condylar guidance of the articulator was adjusted by taking protrusive records. Semianatomic acrylic teeth (Vitapan; Vita Zahnfabrik, Badackingen, Germany) were set in bilateral balanced occlusion. After the try-in visit, the waxedup denture was processed using heat cured denture base material (Acrostone, WHW, England) After processing, laboratory remounting, finishing and polishing; the denture was delivered to the patient. The patient was recalled after one week for occlusal adjustments and inspection. Proper denture hygiene instructions were given to the patient and the denture was periodically evaluated for at least three months before implant insertion. The denture acted as provisional prosthesis for evaluation of occlusion, insuring patient's adaptation and neuromuscular accommodation.

\section{Surgical and prosthetic phases}

In this study, a pre-operative radiograph using cone beam computed tomography (CBCT) machine (Scanora3D, Sorredex- Finland, 15mA, 85 KV) was done for each patient to exclude the presence of any pathology. Implant sites were examined with respect to the residual alveolar bone quality and quantity and selected to design the planning scheme. A surgical guide was fabricated according to the uploaded patient's file using 3D printing technique. The surgical guide contained two metal sleeves related to the predetermined implants sites. To allow for the fixation of the guide with anchor pins during the surgery, three labial and buccal cylinders were included in the surgical guide. Each patient was scheduled for surgery to insert two root form (3.7 $\mathrm{mm}$ in diameter, $16 \mathrm{~mm}$ in length) implants.

Each patient received two implants from the same implant manufacturer with the same design except for the implant-abutment connection. An implant with 12-degree conical internal hex connection (implant direct: interactive ${ }^{\mathrm{TM}}$ no. 653716, USA) was inserted in one side and another implant with trilobe connection (implant direct: Reactive ${ }^{\circledR}$ no.753716) was inserted in the contralateral side. The implants were inserted in the canine region of the mandible using two-stage surgical technique and conventional loading protocol. The Insertion of each type of implant was randomly assigned between the two contralateral sides intraorally for each patient. Each patient was treated according to split mouth design. The insertion was guided by the $3 \mathrm{~d}$ printed surgical guide which was fixed in proper position with anchor pins, then removed after successive drilling and reaching the final preparation with a $3.2 \mathrm{~mm}$ diameter and $16 \mathrm{~mm}$ length drill. Implants were manually inserted with the torque wrench until flushing with bone level and surgical cover screw was screwed to them. Implants remained submerged for three months. The patient's complete denture was relined with tissue conditioner (Recon, Coltne/Whaledent Inc., Cuyahoga Falls, $\mathrm{OH}$, USA). After three months, the implants were exposed and impression copings were screwed to the implants splinted with a stainless-steel wire and duralay. An opened auto-polymerized acrylic resin tray was constructed with an opening opposing the site of impression copings. An elastomeric impression material (Dentsply Aquasil, Dentsply Caulk, Milford, DE, USA) was used to take the impression. The tray was loaded with heavy body rubber base and light body was injected around the copings. The tray was seated intraoraly with exposure of the tightening screws of the impression copings, after setting of the impression material, impression copings were unscrewed and tray was removed from patients mouth. Implant analogues were then screwed to the impression copings, and the impression was poured with stone (Hard type III gypsum, Zeta dent, Italy). Impression coping were unscrewed from implant analogues. The straight 
abutments were screwed to the implant analogue on the cast, prepared parallel to each other. The Cast was placed on a milling machine to ashore the parallelism between the implants' abutments. They were prepared with 2 degrees taper. Waxing up of two telescopic crowns around the abutment was done. These crowns were connected with a meshwork mesially and distally related to the edentulous ridges and extending posteriorly to the area of the second premolar. Investing and casting of the waxed-up framework with basemetal alloy completely was done according to the manufacturer's instructions. Lastly, the metal formwork was finished and polished. Try in of the metal framework intraorally was done. Recording the jaw relation was done and setting-up of artificial teeth was made then checking the trial denture by trying it intraorally was done. The trial denture was flasked and wax was eliminated. Packing of the overdenture was done using heat cured acrylic resin (Acrostone, WHW, England). Processing was accomplished in the conventional way. The overdenture was inserted in the patient's mouth and checked for accurate fitting on the abutments (figure 1). The occlusion was checked and adjusted. The insertion and removal method of the denture was shown to the patient. Proper denture hygiene instructions were given to the patient.

\section{Patients grouping}

The Insertion of each type of implant was randomly assigned between the two contralateral sides intraorally for each patient. Randomization was done utilizing a statistical software program (Minitab 17.0, Pennsylvania, USA). A random number was generated from 0 to 1 , if the random number was less than 0.5 the implant was assigned to be inserted on the left side, otherwise it was inserted in the right side. The results of the randomization were recorded and preserved for each patient for the following patient grouping. Each patient was treated according to split mouth design. The patients were divided into two groups according to the implantabutment connection type

Group A: patients receiving abutments with conical (Morse taper) Implant-abutment connection

Group B: patients receiving abutments with trilobe Implant-abutment connection

\section{Parameters of evaluation}

1. Maximum Bite force: Patient was seated in an up-right position in the dental unit and instructed to bite on the force transducer bite sensor device (occlusal force - meter, GM10, Nagano Kieki.,

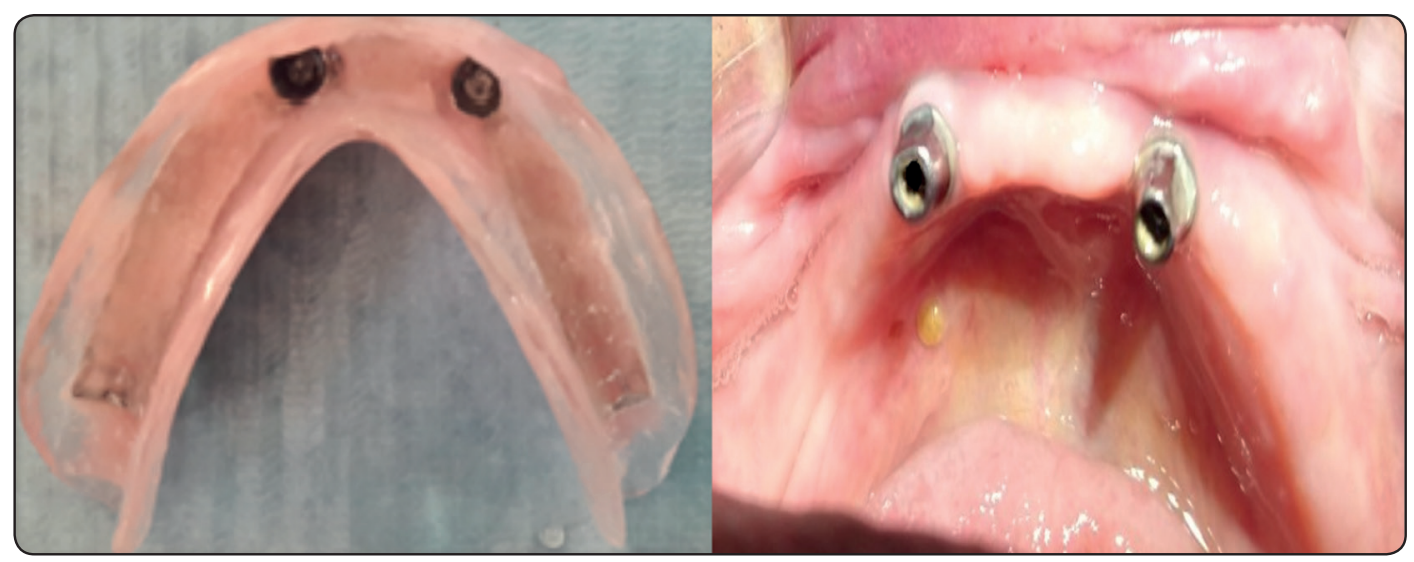

(a) The fitting surface of telescopic overdenture

(b) the primary copings of telescopic crowns intraorally

Fig. (1) The mandibular implant supported telescopic overdenture 
LTD) positioned on the occlusal surface of the mandibular premolar area in one side. Similarly, in contralateral side, it was placed on the occlusal surface of the premolar area. Each patient was instructed to bite as much as he could on the bite sensor. (figure 2) The procedure was repeated three times for each side in each patient with 45 seconds intervals between bite on each side, and the maximum value of the bite force (MBF) was recorded for each side in newtons $(\mathrm{N})$. The readings were recorded instantly at the loading time (0 months), six and twelve months after loading. The maximum bite force for each side was compared to the other side in a splitmouth designed study between group A (conical implant -abutment connection) and group B (trilobe implant -abutment connection).

2. Prosthetic maintenance: prosthetic complications and repairs were documented and compared between the two implant- abutment groups (group A and B) for each patient during the oneyear follow-up period. Patients had planned visits every three months. Patients who had complications or problems during the study period came to the clinic, maintenance service was done and recorded. Prosthetic complications and maintenances related to the implant/abutment/ attachment assembly were recorded and documented..$^{48}$ The Prosthetic complications and maintenances' comparing aspects were abutment screw loosening or fracture, worn or fractured abutment, implant fracture, attachment fracture, wear or corrosion of the retention elements, telescopic crown loosening and matrix activation with adjustment of friction.

3. Peri-implant sulcular fluid (PISF): PISF was collected from the buccal sulcus of each implant in each group. at the time of loading ( 0 months), 6 and 12 months after loading. Sample collection was done during the morning hours from 9 AM to $11 \mathrm{AM}$ after isolating the implant of interest with cotton rolls and drying the external surface of the soft tissues with a gentle stream of air for $5 \mathrm{~s}$. Whatman filter paper strips (Whatman International Ltd Maidstone, England) were utilized, inserted to a maximal depth of $1 \mathrm{~mm}$ (until mild resistance was encountered) in the buccal sulcus and kept in this position for 30 s as recommended by a comprehensive technical review. ${ }^{49}$ Extreme care was taken to minimize mechanical trauma during sampling in order to avoid any effect on the volume of PISF. Any strip that had been contaminated with blood or saliva was discarded. The period between PISF collection and the paper strips transfer to the scale to was minimized to avoid the risk of evaporation. Each strip was weighted in an empty sterilized plastic Eppendorf tube using an electronic digital balance (Electronic balance ATY224, Shimadzu corporation, Kyoto, Japan) before collecting the sulcular fluid. The filter paper with the same plastic Eppendorf tube was reweighted after collection of PISF (figure 3). The difference between the two weights was considered to equal the volume or weight of the collected fluid as the specific gravity is approximately one, hence; volume $=$ weight.$^{50}$

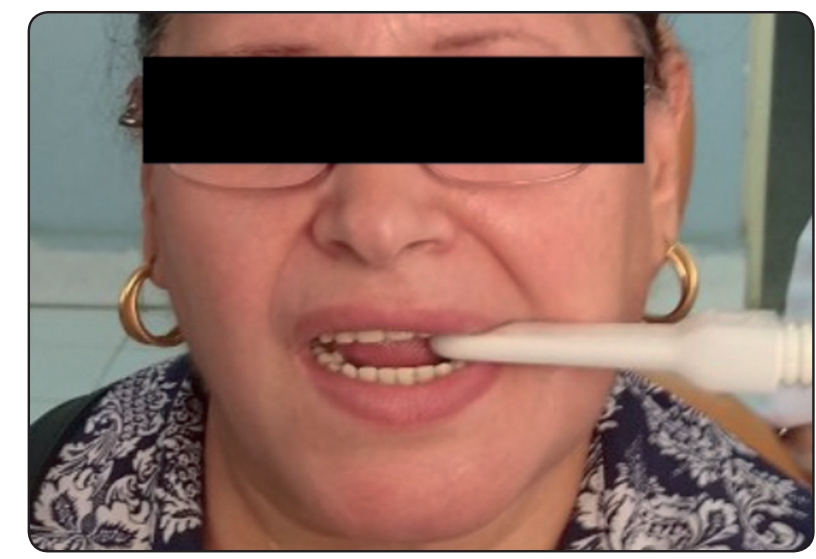

Fig. (2) Maximum bite force measurement 


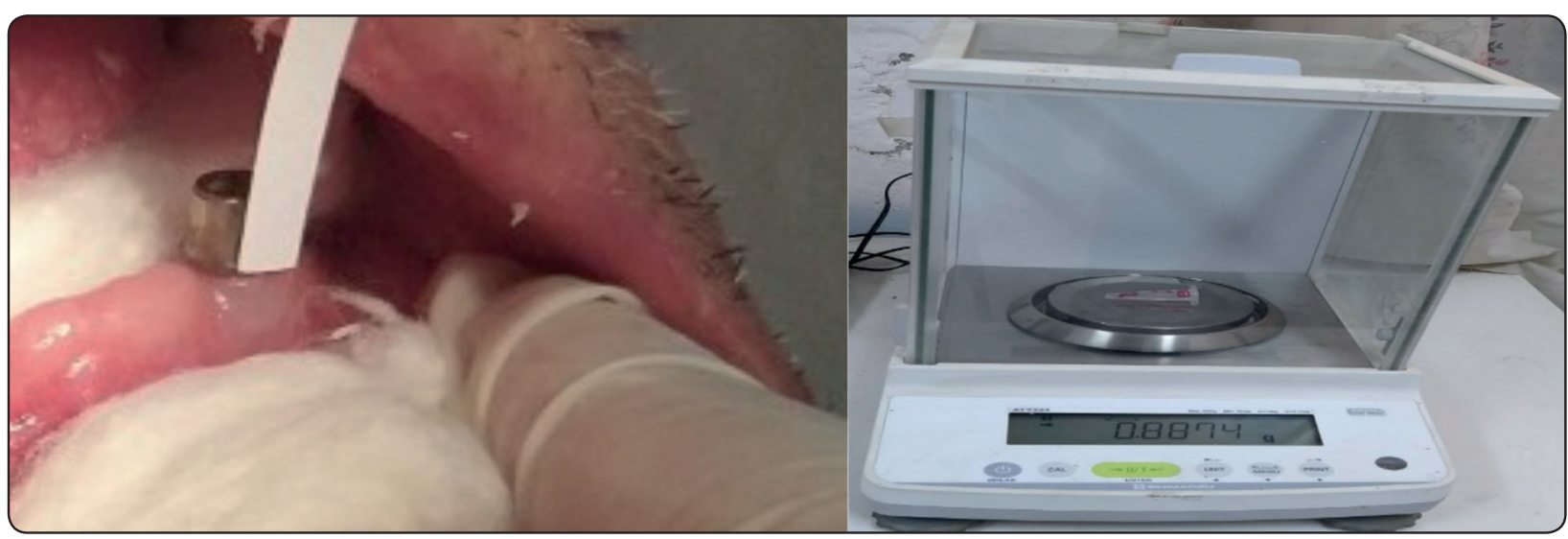

Fig. (3) evaluation of PISF

(Above: Whatman filter paper in the buccal crevice of the implant. Below: Eppendorf tube with strip on digital electronic balance after collection of the crevicular fluid)

\section{Statistical analysis}

The collected data was organized and tabulated. The SPSS statistical package (SPSS Inc., Chi, IL, USA) was used to analyze the data. Data was expressed as mean \pm standard deviation (SD). T-test was used to determine if there is a statistically significant difference in the maximum bite force and the peri-implant sulcular fluid between both groups

\section{RESULTS}

Twenty-four implants were inserted in twelve patients, no implant was lost, resulting in an implant survival rate of $100 \%$ in both groups after an observation period of 12 months.

\section{Maximum Bite force:}

The mean values and standard deviations of the Maximum bite force in Group A (conical) implants were $74.58 \pm 1.78,92.58 \pm 3.50$ and $126.17 \pm 5.24$ at loading time (0 months), six months and twelve months follow up visits respectively. The mean values and standard deviations of the maximum bite force at Group B (trilobe) implants were 73.33 \pm 1.83 , $85.00 \pm 2.37$ and $102.00 \pm 4.02$ at loading time $(0$ months), six months and twelve months respectively. (table 1) There was no statistically significant difference $(\mathrm{P}>0.05)$ in maximum bite force between Group A and Group B at loading time. There was statistically significant difference $(\mathrm{P}<0.05)$ in maximum bite force between Group A and Group $\mathrm{B}$ at six- and twelve-months visits. The maximum bite force showed an obvious increase throughout the whole study period in both groups (from 0 to 12 months) which is shown in figure 4.

TABLE (1) Descriptive statistics and comparison of the maximum bite force between Group A (conical) and B (trilobe)

\begin{tabular}{|c|c|c|c|}
\hline & \multicolumn{3}{|c|}{ Follow up time } \\
\hline Groups & $\begin{array}{c}\text { At loading } \\
\text { Mean } \pm \text { SD }\end{array}$ & $\begin{array}{c}6 \text { months } \\
\text { Mean } \pm \text { SD }\end{array}$ & $\begin{array}{c}12 \text { months } \\
\text { Mean } \pm \text { SD }\end{array}$ \\
\hline Group A (conical) & $74.58 \pm 1.78$ & $92.58 \pm 3.50$ & $126.17 \pm 5.24$ \\
\hline Group B (Trilobe) & $73.33 \pm 1.83$ & $85.00 \pm 2.37$ & $102.00 \pm 4.02$ \\
\hline P- value & $\mathrm{P}>0.05$ & $\mathrm{P}<0.05$ & $\mathrm{P}<0.05$ \\
\hline
\end{tabular}

$* P$-value $<0.05$ was considered significant

\section{Prosthetic maintenance:}

Some prosthodontic or technical complications and maintenance requirements were noted during this one-year study; 6 interventions were needed. One prosthetic complication and maintenance service was recorded and solved in group A (conical). Five prosthetic complications and maintenance services were recorded and solved in group B (trilobe). 


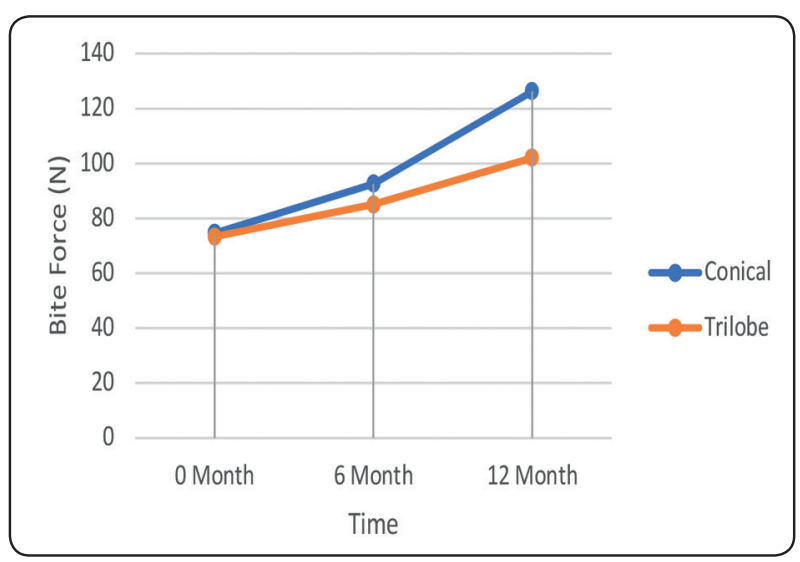

Fig. (4) the maximum bite force of Group A (conical) and B (trilobe) at loading, 6 and 12 months follow up vists

Abutment screw loosening was less frequent in Group A (1 event) compared to Group B (4 events). No screw fracture was recorded in Group A while one event of screw fracture was observed and managed. The total incidence and amount of prosthodontic maintenance in Group A was obviously less than Group B (1 versus 5 interventions). Concerning the rest of items, no maintenance intervention was needed for both groups. Table 2 gives an overview of the maintenance performed for both groups.

TABLE (2) The prosthetic complications and maintenance services in Group A (conical) and Group B (Trilobe) after one year follow up period

\begin{tabular}{|l|c|c|}
\hline $\begin{array}{c}\text { Prosthetic complication and } \\
\text { maintenance service }\end{array}$ & $\begin{array}{c}\text { Group A } \\
\text { (Conical) }\end{array}$ & $\begin{array}{c}\text { Group B } \\
\text { (Trilobe) }\end{array}$ \\
\hline Abutment screw loosening & 1 & 4 \\
\hline Abutment screw fracture & 0 & 1 \\
\hline Implant fracture & 0 & 0 \\
\hline Worn or fractured abutment & 0 & 0 \\
\hline Attachment fracture & 0 & 0 \\
\hline $\begin{array}{l}\text { Wear or corrosion of the } \\
\text { retention elements }\end{array}$ & 0 & 0 \\
\hline $\begin{array}{l}\text { Telescopic crown loosening } \\
\text { (Matrix activation } \\
\text { withAdjustment of friction) }\end{array}$ & 0 & 0 \\
\hline \multicolumn{1}{|c|}{ Total } & 1 & 5 \\
\hline
\end{tabular}

\section{peri-implant sulcular fluid (PISF)}

The mean values and standard deviations of the PISF of Group A (conical) implants were $0.01475 \pm$ $0.00317,0.01008 \pm 0.00178$ and $0.00692 \pm 0.00168$ at loading time ( 0 months), six months and twelve months follow up visits respectively. The mean values and standard deviations of the PISF at Group B (trilobe) implants were $0.01400 \pm 0.00283$, $0.01050 \pm 0.00220$ and $0.00683 \pm 0.00204$ at loading time (0 months), six months and twelve months respectively. There was no statistically significant difference $(\mathrm{P}>0.05)$ in PISF between Group A and $\mathrm{B}$ at loading time, six and twelve months follow up visits (table 3 )

TABLE (3) Descriptive statistics and comparison of the PISF between Group A (conical) and B (trilobe)

\begin{tabular}{|c|c|c|c|}
\hline & \multicolumn{3}{|c|}{ Follow up time } \\
\hline Groups & $\begin{array}{c}\text { At loading } \\
\text { Mean } \pm \text { SD }\end{array}$ & $\begin{array}{c}6 \text { months } \\
\text { Mean } \pm \text { SD }\end{array}$ & $\begin{array}{c}12 \text { months } \\
\text { Mean } \pm \text { SD }\end{array}$ \\
\hline $\begin{array}{c}\text { Group A } \\
\text { (conical) }\end{array}$ & $\begin{array}{c}0.01475 \pm \\
0.00317\end{array}$ & $\begin{array}{c}0.01008 \pm \\
0.00178\end{array}$ & $\begin{array}{c}0.00692 \\
\pm 0.00168\end{array}$ \\
\hline $\begin{array}{c}\text { Group B } \\
\text { (Trilobe) }\end{array}$ & $0.01400 \pm$ & $0.01050 \pm$ & 0.00683 \\
\hline P- value & $\mathrm{P}>0.05$ & $\mathrm{P}>0.05$ & $\mathrm{P}>0.05$ \\
\hline
\end{tabular}

$* P$-value $<0.05$ was considered significant

\section{DISCUSSION}

In terms of long-term success of dental implant treatment, stability and precision of implant components connection must be accomplished. Implant abutment connection is a chief factor of stability and strength of the implant supported overdenture as it is the transition from the surgical phase to the prosthetic phase. Modifications in the implant-abutment connection design is one of the parameters most altered by the manufacturers. The reason of these alterations is an attempt to 
create better prosthetic stability, reduce stress on bone-implant interface and decrease the implantabutment gap that is reported in various implant systems..$^{51}$ Also, the preservation of the peri-implant bone height is controlled with mechanical and microbiological characteristics of the implantabutment connection. ${ }^{52}$

Conical connection systems provide superior bacterial seal and resistance to abutment movement, fatigue loading, maximum bending, torque loss compared to other connection systems. ${ }^{14}$ However, these features of conical connection might theoretically offer improved clinical outcomes, no evidence or consensus is available. Comparative clinical studies assessed only the success rate and marginal bone loss in implants with different connection. Although the Conical implant-abutment connections are known with its anti-bending performance Mechanical performance of conical implant-abutment connections under different cyclic loading conditions, the axial and torsional forces play important roles in occlusion. ${ }^{53}$ So far, there were rare studies on their effects on connection anti-torsional stability. The loading circumstances in the oral cavity is a complex process that guided by neuromuscular control. There is lack of evidence if there is a relationship between implant-abutment connection design and maximum bite forces of patients.

The maximum bite force showed significant improvement throughout the whole study follow up period in both implants groups which is an indication of better patient adaptation and neuromuscular control of the prosthesis. Additionally, implant supported overdentures improve maximum bite force and masticatory performance, increase patient satisfaction and minimize pain during chewing. ${ }^{40-44,46}$ Also, the telescopic attachment system -compared with other attachments- provides outstanding retention due to frictional fit between primary and secondary copings. It offers better distribution of forces, mechanical durability and reduced denture movement. It can offer a treatment option with increased retention thus improving masticatory function of patients. The results of the current study confirm the advantageous effects of implant supported overdenture on maximum bite force and chewing efficiency which have been reported in other studies. ${ }^{54,55}$

There was a statistically significant difference between the maximum bite force of the conical connection implant group compared to that of the trilobe implant group at six and twelve months follow up visits. This can be attributed to the self-locking mechanism of conical connections providing a tight contact pressure between the abutment and the implant reducing the microgap size significantly. Additionally, conical connections possess a frictional resistance stabilizing the abutment to the implant, altering two-piece connections to function as a single piece. Consequently, the conical connections provide a superior mechanical performance and lower micromotion of the abutment resulting in their reliable implant-abutment connection stability ${ }^{53,56,57}$ All these superior qualities inherited in the conical implant connection may have motivated the patients and encouraged them to bite more efficiently on the conical implant side, therefore the maximum bite force increased significantly after six and twelve months follow up periods. This finding contradicts the results of a previous study which investigated the magnitude of micromotion in different implant abutment interfaces. It was found that the conical Implant-abutment connection showed the highest magnitude of micromotion, whereas the trilobe connection presented the lowermost magnitude of micromotion owing to its polygonal profile..$^{58}$ However, this could be attributed to the fact that the latter study was a $3 \mathrm{~d}$ finite element analysis and the current study was a clinical study.

Implant failures can be divided into biological, functional mechanical and iatrogenic. Failure can 
possibly originate from implant overloading or from the bacterial infection of the peri-implant tissues. ${ }^{59}$ The most common failure accompanying dental implants is screw loosening and implant fracture. One of the chief reasons of screw loosening is the "preload loss". ${ }^{60}$ Screw loosening can be an indication of occlusal overloading and/or inadequate biomechanical prosthetic reconstruction design. Loosened or fractured screws may cause expensive complications. During the follow up period of the current study, the group of implants with conical (Morse taper) implant-abutment connection have reported a reduced incidence of prosthetic complications and maintenances services needed, compared with the trilobe implantabutment connection group of implants. This result can be attributed to the superior mechanical characteristics of the conical connection reducing stresses in the implant abutment interface thus fewer complications were encountered. This finding is in accordance with the results of several studies. These studies concluded that the conical implantabutment connection reported the least prosthetic complications compared to other implant-abutment connections. ${ }^{36,37}$

The gingival index, probing depth and bleeding index are clinical indices lacking the ability to accurately evaluate the onset and progression of peri-implant destructive changes. They cannot foresee the risk of peri-implantitis. It is crucial to distinguish the occurrence of inflammation in its early phases because early implant failure pose an excessive financial load to both the clinician and the patient. The peri-implant tissues clinical assessment is essential to perceive early signs of disease and properly performing therapeutic interventions. ${ }^{27}$ The early diagnosis of peri-implantitis and peri-implant mucositis, especially in their early phases, is critical to decrease the necessity of treating an active periimplantitis. The PISF volume increased with the increase of the extent and degree of inflammation. ${ }^{28}$ Therefore, the PISF volume can be an indicator more proficient for investigating the peri-implant mucosal inflammation progress. Hence, the clinical volume detection of PISF could be clinically useful in evaluating and foreseeing the peri-implant tissues response thus improving the long-term implants success. ${ }^{27}$ The evaluation of PISF volumes is a simple, non-invasive, rapidly accomplished method to provide an early diagnosis. ${ }^{61}$

Regarding PISF, there was no statistically significant difference between the PISF between conical and trilobe group at loading time, six and twelve months follow up visits. The values of the PISF decreased with time throughout the whole study follow up period (12 months) in both groups. This is possibly owing to the meticulous oral and denture hygiene followed, and to the trials done to decrease and distribute the load widely. The studies regarding the quantification of fluid leakage and passage between different connection designs are scarce. Most of them were invitro studies comparing implant-abutment microgaps and bacterial leakage. An invitro study compared conical to trilobe implant-abutment connections in terms of bacterial leakage concluded that leakage in conical connection was significantly less than trilobe connections. However, the latter study was an invitro study and comparing bacterial leakage in contrast to the current invivo study. Hence, results are different due to the nature of oral cavity environment and the complex masticatory stresses.

\section{CONCLUSION}

Within the limitations of this study, it can be concluded that the conical implant- abutment connection is associated with increased maximum bite force compared to the trilobe Implant-abutment connection. Conical implant-abutment connection can provide a stable implant system with fewer prosthetic complications and maintenance services compared to trilobe implant -abutment connections. 


\section{REFERENCES}

1. Raghoebar G, Meijer H, Stegenga B and Vis sink A. A randomized prospective clinical trial on the effectiveness of three treatment modalities for patients with lower denture problems: An IO-year follow-up study on patient satisfaction. Int. J. Oral Maxillofac. Implants. 2003; 32: 498-506.

2. Pasciuta M, Grossmann Y and Finger I. A prosthetic solution to restoring the edentulous mandible with limited Inter-arch space using an implant-tissue-supported overdenture: A clinical report. J. Prosthet. Dent. 2005; 93:116-120.

3. Thomason JM. The McGill consensus statement on overdentures. Mandibular British Society for the Study of Prosthetic Dentistry. The York consensus statement on implantsupported overdentures. Eur J Prosthodont Restor Dent. 2009; 17: 164-165.

4. Krennmair G, Weinländer $\mathrm{M}$, Krainhöfner, $\mathrm{M}$ and Piehslinger E. Implant-Supported Mandibular Overdentures Retained with Ball or Telescopic Crown Attachments: A 3-Year Prospective Study. Int J Prosthodont. 2006;19:164-170.

5. Elsyad MA, Khairallah AS and Shawky AF. Changes in the edentulous maxilla with ball and telescopic attachments of implant-retained mandibular overdentures: a 4-year retrospective. 2013; 44 (7) : 487-495.

6. Heckmann SM, Schrott A, Graef F, Wichmann, MG and Weber HP. Mandibular two-implant telescopic overdentures. Clinical Oral Implants Research. 2004;15: 560-569.

7. Prithviraj D R, Ninad M, and Vikas G. The Evolution of External and Internal Implant-Abutment Connections: A Review of literature. Int J Oral Implantol Clin Res. 2012;3(3):122-129.

8. Jarman JM, Hamalian T, Randi AP. Comparing the Fracture Resistance of Alternatively Engineered Zirconia Abutments with Original Equipment Manufactured Abutments with Different Implant Connection Designs. Int J Oral Maxillofac Implants. 2017;32:992-1000.

9. Sarfaraz H, Paulose A, Shenoy K and Hussain A. A three-dimensional finite element analysis of a passive and friction fit implant abutment interface and the influence of occlusal table dimension on the stress distribution pattern on the implant and surrounding bone $\mathrm{J}$ Ind Prosthodont Soc. 2015 ; 15(3): 229-236.

10. Teixeira W, Ribeiro R, Sato S, and Pedrazzi V. Microleakage into and from two-stage implants: an in vitro comparative study. Int j Oral maxillofac implants,2011;26(1):56-62.
11. Meleo D, Baggi L and Di Girolamo M. Fixture-abutment connection surface and microgap measurements by 3D microtomographic technique analysis. Ann 1st Super Sanità. 2012; 48:53-58.

12. Shelat S, Kularashmi BS, Annapoorani $\mathrm{H}$ and Chakravarthy R. Effect of two different abutment types on stress distribution in the bone around an implant under two loading conditions. J Dent Implant. 2011; 1:80-91.

13. Quaresma SE, Cury PR, Sendyk WR and Sendyk C. A finite element analysis of two different dental implants: Stress distribution in the prosthesis, abutment, implant, and supporting bone. J Oral Implantol. 2008; 34:1-6.

14. Schmitt CM, Nogueira-Filho G, Tenenbaum HC, Lai JY, Brito C, Döring H and Nonhoff J. Performance of conical abutment (Morse Taper) connection implants: a systematic review. J Biomed Mater Res A 2014;102(2):552-74

15. Assenza SB, Tripodi D, Scarano A, Perrotti V, Piattelli A, Iezzi G and D'Ercole S. Bacterial Leakage in Implants With Different Implant-Abutment Connections: An In Vitro. J Periodontol. 2012;83:491-497.

16. Tsuruta K, Ayukawa Y, Matsuzaki Y, Kihara M and Koyano K. The influence of implant-abutment connection on the screw loosening and microleakage International J Implant Dent. 2018;4(1):11-18.

17. Bilhan H, Kutay O, Arat S, Cekici A and Cehreli MC. Astra Tech, Branemark, and ITI implants in the rehabilitation of partial edentulism: two-year results. Implant Dent. 2010; 19: 437-446.

18. Pieri F, Aldini NN, Marchetti C and Corinaldesi G. Influence of implant-abutment interface design on bone and soft tissue levels around immediately placed and restored single-tooth implants: a randomized controlled clinical trial. The International Journal of Oral \& Maxillofacial Implants. 2011; 26: 169-178.

19. Koo KT Lee EJ Kim JY Seol YJ Han JS and Kim TI. The effect of internal versus external abutment connection modes on crestal bone changes around dental implants: a radiographic analysis. J Periodontol. 2011; 83:1104-1109.

20. Nishioka RS, de Vasconcellos LG and de Melo Nishioka GN Comparative strain gauge analysis of external and internal hexagon, Morse taper, and influence of straight and offset implant configuration. Implant Dent. 2011;20: e24-e32.

21. Chu CM, Huang HL, Hsu JT, Fuh LJ. Influences of internal tapered abutment designs on bone stresses around a dental implant: three-dimensional finite element method with statistical evaluation. J Periodontol.2012; 83:111-118. 
22. Nascimento C, Barbosa RE, Issa JP, Watanabe E, Ito IY and Albuquerque RF. Bacterial leakage along the implantabutment interface of premachined or cast com ponents. Int J Oral Maxillofac Surg 2008; 37:177-180.

23. Harder S, Dimaczek B, Ac, il Y, Terheyden H, Freitag-Wolf $\mathrm{S}$ and Kern M. Molecular leakage at implant abutmentconnection - in vitro investigation of tightness of internal conical implant-abutment connections against endotoxin penetration. Clin Oral Investig. 2010; 14:427-432.

24. Saidin S, Abdul Kadir R, Sulaiman E and Abu Kasim N. Effects of different implant-abutment connections on micromotion and stress distribution: Prediction of microgap formation. J Dent. 2012;40: 467-474.

25. Covani U, Marconcini S, Crespi R and Barone A. Bacterial plaque colonization around dental implant surfaces. Implant Dent. 2006; 15:298-305.

26. Lachmann S, Kimmerle-Müller E, Axmann D, Scheideler L, Weber $\mathrm{H}$ and Haas R. Associations between peri-implant crevicular fluid volume, concentrations of crevicular inflammatory mediators, and composite IL-1A -889 and IL-1B +3954 genotype. A cross-sectional study on implant recall patients with and without clinical signs of peri-implantitis. Clin. Oral Implants Res. 2007;18 (2): 212 - 223

27. Bhardwaj S and Prabhuji ML. Comparative volumetric and clinical evaluation of peri-implant sulcular fluid and gingival crevicular fluid. J. Periodontal Implant Sci. 2013;43(5):233-242.

28. Avinash Kaur1 and Om P. and Kapoor P and Kalyanasundaram D. A review of biomarkers in peri-mini screw implant crevicular fluid (PMICF) Kaur et al. Progress in Orthodontics. 2017; 18:42-51.

29. Papaspyridakos P, Chen CJ, Chuang SK, Weber HP and Gallucci GO. A systematic review of biologic and technical complications with fixed implant rehabilitations for edentulous patients. Int J Oral Maxillofac Implants. 2012; 27:102-10.

30. Keshk AM, Alqutaibi A, Algabri RS, Swedan MS and Kaddah A. Prosthodontic maintenance and peri-implant tissue conditions for telescopic attachment-retained mandibular implant overdenture: Systematic review and metaanalysis of randomized clinical trials. Eur J Dent. 2017; 11(4): 559-568.

31. Ricomini A, Frederico F,Fernandes S, Straioto S, José Da Silva W and Del Bel A. Preload Loss And Bacterial Penetration On Different Implant-Abutment Connection Systems. Cury Braz Dent J. 2010; 21(2): 123-129.
32. McGlumphy EA, Mendel DA and Holloway JA. Implant screw mechanics. Dent Clin North Am. 1998; 42:71.

33. Khraisat A, Stegaroiu R, Nomura S and Miyakawa O. Fatigue resistance of two implant/abutment joint designs. J Prosthet Dent. 2002; 88:604-612.

34. Khraisat A, Hashimoto A, Nomura S and Miyakawa O. Effect of lateral cyclic loading on abutment screw loosening of an external hexagon implant system. J Prosthet Dent. 2004; 91:326-333.

35. Alkan I, Sertgoz A and Ekici B. Influence of occlusal forces on stress distribution in preloaded dental implant screws. J Prosthet Dent. 2004; 91:319-326.

36. Assenza B, Scarano A and Leghissa G. Screwed versus cemented implant-retained restorations. An experimental study in the beagle dog. Part 1 . Screw and abutment loosening. J Oral Implantol. 2005; 31:242-246.

37. Scarano A, Assenza B and Piattelli M. Retrospective evaluation of the microgap between implants and abutments in 272 titanium implants retrieved fromman: A 16 years' experience. J Oral Implantol. 2005; 31:269-275.

38. Verma TP, Kumathalli KI, Jain V and Kumar R. Bite force recording devices - A review. J Clin Diagn Res 2017;11: ZE01-5.

39. Borie E, Orsi IA, Fuentes R, Beltrán V, Navarro P and Pareja F. Maximum bite force in elderly indigenous and non-indigenous denture wearers. Acta Odontol Latinoam 2014; 27:115-9.

40. Farias Neto A, Pereira BM, Xitara RL, Germano AR, Ribeiro JA, Mestriner Junior W and Carreiro Ada F. The influence of mandibular implant-retained overdentures in masticatory efficiency. Gerodontology 2012; 29: e650e655.

41. Toman M, Toksavul S, Sarac og $\breve{l u, ~ A, ~ C u r a ~ C ~ a n d ~ H a t i-~}$ poglu A. Masticatory performance and mandibular movement patterns of patients with natural dentitions, complete dentures, and implant-supported overdentures. The International Journal of Prosthodontics 2012; 25: 135-137.

42. Boven GC, Raghoebar GM, Vissink A, and Meijer HJ. Improving masticatory performance, bite force, nutritional state and patient's satisfaction with implant overdentures: a systematic review of the literature. Journal of Oral Rehabilitation 2015; 42: 220-233.

43. Van der Bilt A, Speksnijder CM, de Liz Pocztaruk $\mathrm{R}$ and Abbink JH. Digital image processing versus visual assessment of chewed two-colour wax in mixing ability tests. Journal of Oral Rehabilitation. 2012; 39: 11-17. 
44. Geckili, O, Bilhan H, Mumcu E, and Tuncer N. The Influence of Maximum Bite Force on Patient Satisfaction and Quality of Life of Patients Wearing Mandibular Implant Overdentures. Journal of Oral Implantology, 2012; 38 (3): 271 - 271.

45. Fontijn-Tekamp FA, Slagter AP, Van Der Bilt A, Van 'T Hof MA, Witter DJ and Kalk W. Biting and chewing in overdentures, full dentures, and natural dentitions. J Dent Res 2000; 79:1519-24.

46. Lam VT, Kanazawa M, Myat TK, and A M, Sato D, and Minakuchi, S. Masticatory function and bite force of mandibular single-implant overdentures and complete dentures: a randomized crossover control study. Journal of Prosthodontic Research, 2019; 63 (4): 428 - 433

47. Fueki K, Kimoto K, Ogawa T, and Garrett NR. Effect of implant-supported or retained dentures on masticatory performance: A systematic review. Journal of Prosthetic Dentistry. 2007; 98: 470-477.

48. Badr A. Patient satisfaction and prosthetic maintenance within-subjects treated with conventional complete denture and telescopic implant overdentures. 2017; 63: 399:408.

49. Wassall RR. and Preshaw PM. Clinical and technical considerations in the analysis of gingival crevicular fluid. Periodontol 2000. 2016;70 (1): 65-79.

50. Giannopoulou C, Demenisse C and Cimasoni G. Neutrophils elastase and its inhibitors in human gingival crevicular fluid during experimental gingivitis. J. of Dental Research. 1992; 71: 359-363.

51. Singla S and Rathee M. Platform switching: Hype or reality? Indian J Dent Res., 2015; 26 (6): 652-653.

52. Kim JC, Lee J, Kim S, Koo KT, Kim HY and Yeo IL. Influence of implant-abutment connection structure on periimplant bone level in a second molar: A 1-year randomized controlled trial. J Adv Prosthodont. 2019; 11(3): 147-154.

53. Usang-Ta Y, Hung-Chan K, Cheng-Kung C, Hsu-Wei F, Chang-Hung H, Ming-Lun H. Mechanical performance of conical implant-abutment connections under different cyclic loading conditions. Journal of the Mechanical Behavior of Biomedical Materials 90 (2019) 426-432.

54. Grover M, Vaidyanathan AK and Veeravalli PT. Masticatory performance and crestal bone loss with single-implant, magnet-retained mandibular overdentures withconventional and shortened dental arch. Clin Oral Implants Res 2014; 25 (5):580-6.

55. Elsyad MA and Khairallah AS. Chewing efficiency and maximum bite force with different attachment systems of implant overdentures: a crossover study. Clin. Oral Impl. Res. 2017; 28: 677-682.

56. Mishra, SK, Chowdhary, R and Kumari, S. Microleakage at the different implant abutment interface: a systematic review. J. Clin. Diagn. Res. 2017; 11:ZE10-ZE15.

57. Wiest W, Zabler S, Rack A, Fella C, Balles A, Nelson K, Schmelzeisen R and Hanke, R. In situmicroradioscopy and microtomography of fatigue-loaded dental two-piece implants. J. Synchrotron Rad. 2015; 22: 1492-1497.

58. Saidin S, Kadir, MRA, Sulaiman E. and Abu kasim NH. Effects of different implant-abutment connections on micromotion and stress distribution: Prediction of microgap formation. Journal of Dentistry, 2012; 40: 467-474.

59. Tonetti MS and Schmid J. Pathogenesis of implant failures. Periodontol. 2000. 1994; 4: 127-138.

60. Nithyapriya S, Ramesh AS, Kirubakaran A, Mani J and Raghunathan J. Systematic analysis of factors that cause loss of preload in dental implants. J Indian Prosthodont Soc 2018; 18:189-95.

61. Lorenzo B, Matteo DB, Maria GL, Costanza F and Daniele A. Volumetric Analysis of Gingival Crevicular Fluid and Peri-Implant Sulcus Fluid in Healthy and Diseased Sites: A Cross-Sectional Split-Mouth Pilot Study. Open Dent J. 2016; 10: 131-138. 